\title{
Share or not to share? Sharing economy in public eyes
}

\author{
Vladislav Kaputa ${ }^{1, *}$, Miroslava Triznová ${ }^{,}$Hana Mat'ová $^{1}$, and Mikuláš Šupín ${ }^{1}$ \\ ${ }^{1}$ Technical University in Zvolen, Faculty Wood Sciences and Technology, Department of Marketing, \\ Trade and World Forestry, T. G. Masaryka 24, 96001 Zvolen, Slovakia
}

\begin{abstract}
.
Research background: Sharing (or collaborative) economy brought a bulk of possibilities to spread the business internationally not only for private sector, but also for every citizen who own any assets demanded on the market. With a vital support of web platforms even individuals can utilise shared goods and services either as a supplier or as buyer.

Purpose of the article: The study aims at the assessment of public attitudes towards the phenomenon of sharing economy. More detailed, the willingness to utilise shared services and goods as well as the willingness to offer them are investigated.

Methods: The questionnaire survey was conducted to reveal the public attitudes towards selected aspects of sharing economy. Dominantly, the Likert-type scale is used to express respondents' attitudes, but also the method of semantic differential was utilised. It is used as the 7-points rating scale designed to measure the connotative meaning of the sharing economy concept. The questionnaire was distributed among public using purposive sampling via web platforms. The frequency and contingency analyses with support of the relevant statistics are used to process the data. Findings \& Value added: The survey reached mostly young people which is positively perceived as lot of "web-skilled" individuals could be expected among such a sample. Internet literacy is a pre-cursor for sharing economy possibilities utilisation. Surprisingly, higher share respondents do not expressed interest to offer services via sharing economy platforms. Overall, no more than $30 \%$ of the sample utilise shared services. Here, men seem to be more embraced to be involved.
\end{abstract}

Keywords: sharing economy; public; survey; attitudes; services

JEL Classification: $A 19 ; D 16 ; F 69$

\footnotetext{
*Corresponding author: kaputa@tuzvo.sk
} 


\section{Introduction}

Economy, as a science, deals with the utilisation of limited resources for the production of useful assets and services and their subsequent distribution to different groups in society. Economics study how and why people (as consumers, corporates, NGOs, public sectors or government agencies) make decisions about the use of valuable resources [1]. In recent years, the economy has undergone changes and new ways of interaction between consumers and companies. As mentioned by Mat'ová et al. [2], facing recent global changes, we are not just spectators of this "theatre", we are part of it, we are actors. One of the behavioural change among companies and consumers is rising willingness to share. Sharing economy or collaborative consumption is when peers are actively sharing goods and services, and it is supported by community based platforms [3]. This is related with economic crisis in 2008 which accelerated sharing economy and was firstly related with cost saving. Since then and with the development of IT, and sharing economy or collaborative consumption is rising trend [4]. Now days the variety of digital sharing platforms is rising. Digital sharing platforms according their motivation and business model can aim on: i) social interaction, ii) profit and sustainability or iii) can aim on mixed areas [5].

Sharing economy is reducing waste by "swapping, gifting, trading, lending or bartering underused or unwanted goods" [6]. There are different motives why are people willing to share. The study by Lang [7] who aimed on psychological factors, showed that the trust and gratitude have positive effect on consumers to become providers of the service. Trust is ability to count on individual, group or company [8]. To be trustworthy, provider has to prove its own character (e.g., competence, credibility, trustworthiness), its actions toward consumer (e.g., efficiency, reliability) or output (e.g. level of quality of product or service, or service itself) [9]. Gratitude is emotion that comes of action of others who have voluntarily and intentionally made good deed toward oneself [10]. It means when one is experiencing good trustworthy service, and this service is overcoming ones' expectations person can feel gratitude. Consumers who experienced such a service are more willing to adopt the role of the provider in the sharing economy in the future [7]. Nadeen [11] confirmed, that being cared and understood - (multidimensional social support), has strong impact to value co-creation trough sharing economy platforms.

Motivation for participating in sharing economy can be affected by different areas. When taking into consideration economic factor, motivation is different among consumers and among companies [12]. Consumers look for convenience and value. Providers are motivated by creating better community and increase sustainability [13]. Some scholars took into consideration lifestyle as motivation to participate: personal motivation economic advantages, social motivations - to be like others, and ideological motivations to help the world [14]. People participation in sharing economy can be also motivated by values: inner symbolic, hedonic and economic values. This values are related with personal attitudes one have toward sharing economy and they lead person into behaviour. Study of millennials respondents identified symbolic (altruistic) value as the strongest predictor of willingness to participate in sharing economy. The hedonic value (emotion fun enjoyment) was placed as second, and economical value was identified as weakest predictor of millennials sharing intention and behaviour [4].

When taking into account age and motivation to participate in sharing economy. The young people with free time and limited income are willing to participate in sharing economy not only because of personal motivation (financial savings) but also ideological ones, they are aware of environmental problems. Older wealthy subjects, have lifestyle motivation to participate in sharing economy that is rooted in conformist social motivation. 
Younger subjects are opened to new experiences, older respondents were looking for economic benefits and convenience [14]. Younger people who are environmentally and healthy conscious, take risk and have positive relationship toward digitalisation, are more willing to participate in sharing economy [15].

Sharing was based on linear interaction between service/product consumer and provider. Development of information technology enabled to create interactive sharing business platforms. "Central to success of sharing economy platform business is their ability to generate network effect" [7]. The more providers are registered at platforms, the larger is offer for consumers. It works vice versa, the more consumers are registered at platforms, the larger is potential market for providers. There is potential, that consumers can also become both consumer and provider - "prosumers" [7]. In order to create sustainable competitive advantage at high profits sharing economy service have to have market orientation: to reflect consumer respondents; identify user potential desires and share value between service and user [16]. Development of information technologies dynamic, and with this development comes also question of the security and privacy in sharing economy [17]. Platforms where come consumers and providers, also consumers and providers, - all three parts of this triangular exchange in share economy have to prove as worthy of trust. For millennials trust matters more in some sharing encounters than in others. Trust is for millennials more important in encounters, that need higher financial investment and require more social interaction [18]. Gen X (35-49) believed, that the level of risk in sharing economy is high, Gen Y (21-34) believed, that the level of risk in sharing economy is high, and Gen Z (under 20) believed, that the level of risk in sharing economy is relatively low. This risk factor had relatively small effect on Gen X, large impact on Gen $\mathrm{Y}$ and small effect on Gen Z [17].

Current scholars dealing with business perspective of sharing economy are consistent that: sharing economy is not sustainable without understanding sharing practices of the resource owners and resource users. This might lead to the sustainability and evolution of business models in sharing economy [19].

\section{Methods}

The objective of the paper is to evaluate the Slovak public's attitudes to selected aspects of the sharing economy. More detailed, the willingness to utilise shared services and goods as well as the willingness to offer them were investigated.

The design and construction of the questionnaire survey as the primary research tool was the basic precondition to fulfil the objective of the study. We gathered also identification data regarding the sex, age, residence, and social status of the respondents. The answers were constructed using the 5-points Likert-type scale (1-definitely yes, 2rather yes, 3-indifferent attitude, 4-rather no, 5-definitely no) except of questions dealing with frequency of activity. Questions dealt with:

- utilisation of the introduced possibilities of the sharing economy,

- consideration of offering sharing economy services,

- agreement with the defined claims (treated in this paper).

Semantic differential was also used to measure the attitudes. We chose 11 different antonyms, which were aspects for the evaluation of the sharing economy by public. It is used as the 7-points rating scale.

The questionnaire was distributed among public using purposive sampling. Link related to the electronic form of the questionnaire was distributed using web platforms. We have reached 232 completed forms. Frequency and contingency analyses were used for data processing. Data obtained by semantic differential were analysed using arithmetic mean. 


\section{Results}

Totally, 232 respondents took part in the survey, while the share of women (58\%) exceeded the share of men $(42 \%)$. The respondents were categorised into three age groups, the first of which included those aged 18 to 25 years as the largest group (72\%) created mostly by students. Most respondents (53\%) come from the rural areas.

Table 1. Demography of respondents $(n=232)$

\begin{tabular}{|l|c|}
\hline Sex & Percentage (\%) \\
\hline Women & 58 \\
\hline Men & 42 \\
\hline Age category & Percentage (\%) \\
\hline 18-25 years old & 72 \\
\hline 26-35 years old & 17 \\
\hline over 36 years old & 11 \\
\hline Residence & Percentage (\%) \\
\hline Rural area & 53 \\
\hline Urban area & 47 \\
\hline Social status & Percentage (\%) \\
\hline Student & 72 \\
\hline Employee & 18 \\
\hline Maternity leave & 4 \\
\hline Unemployed & 2 \\
\hline Pensioner & 2 \\
\hline Entrepreneur & \\
\hline
\end{tabular}

Semantic differential was designed to measure the connotative meaning of the shared economy concept. Points of the arithmetic mean in the Graph 1 show the differences between the expressed attitudes of men and women. With the exception of one item (dealing with security), all others were perceived to some extent positively by both categories, men and women. Although, apart from the item on whether the sharing economy is expanding, women perceive all aspects somewhat more positively than men. The sharing economy was rated the most differently between the sexes (by 0.4 points) in three items, where women rated it as simpler, more accessible and more comfortable (Graph 1). 


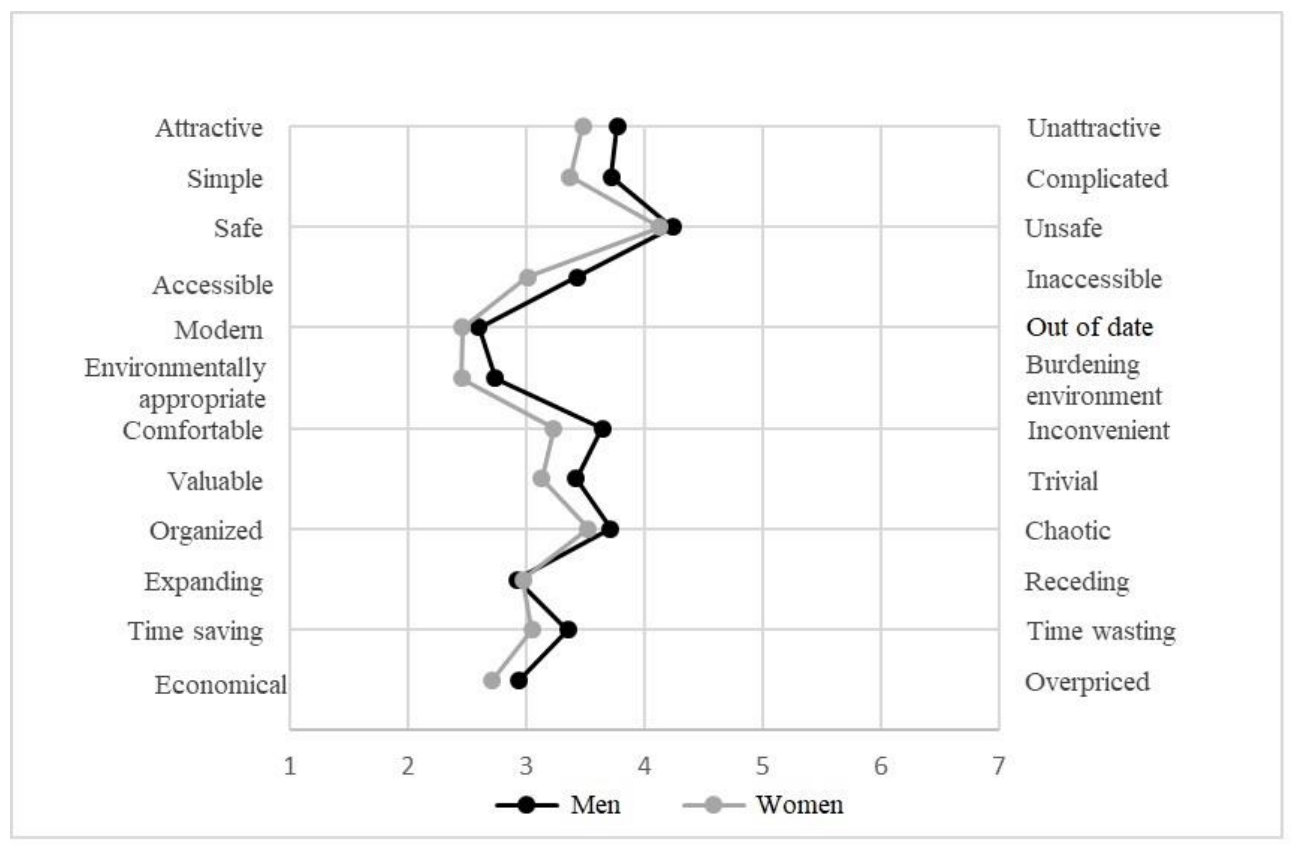

Fig. 1. Evaluation of the "use of the sharing economy" by the semantic differential between men and women.

Contingency analysis pointed at the differences between the expressed attitudes of inhabitants from rural and urban areas. With the exception of the item "safe", all other items were perceived positively to some extent. Respondents coming from the urban areas perceive most of aspects somewhat more positively comparing those coming from rural areas. Considering most differently rated items, respondents from urban areas consider "using of sharing economy" as more simple, more modern, more environmentally appropriate, and more valuable.

Table 2 presents an interesting insight at public opinion on the investigated phenomenon revealing that almost half of the respondents have positive attitudes towards the sharing economy and its impact on the state, self-governments, the social status of citizens, and the environment. Contingency analyses revealed that respondents aged over 36 years have the highest share of positive attitudes $-64 \%$ in the case of the state and $68 \%$ in the case of self-government. The use of web platforms for civic advertising is perceived as helping in the current epidemic by more than $45 \%$ of respondents. A clear reference is made regarding the relationship between the sharing of goods and the state of the environment. About $60 \%$ of the sample agree that sharing helps not to burden the environment.

Overall, Table 2 shows a high share of indifferent attitudes - more than one third of the sample in each of the first four examined claims. The fact that sharing of goods helps not to burden the environment is rational since no new production is needed, which also reduces material demands, etc. A balance of the shares of responses to the claims "Sharing economy improves the social status of citizens“ and „Web platforms for citizens' advertising help their actors in the current epidemic" can be observed. In both cases, the possibility to share the assets of individuals is assessed as socially beneficial. 
Table 2. Public attitudes to selected aspects of the sharing economy $(n=232)$

\begin{tabular}{|c|c|c|c|}
\hline \multirow{2}{*}{ Sharing economy is good for the state } & \multicolumn{3}{|c|}{ Attitude (\% of the sample) } \\
\cline { 2 - 4 } & Agree & Indifferent & Disagree \\
\hline Sharing economy is good for self-governments & 44.0 & 37.1 & 19.0 \\
\hline Sharing economy improves the social status of citizens & 54.3 & 34.5 & 11.2 \\
\hline $\begin{array}{c}\text { Web platforms for citizens' advertising help their actors in the } \\
\text { current epidemic }\end{array}$ & 45.7 & 43.1 & 11.2 \\
\hline $\begin{array}{c}\text { The sharing of goods by citizens helps not to burden the } \\
\text { environment }\end{array}$ & 60.3 & 28.9 & 10.8 \\
\hline $\begin{array}{c}\text { Would you use sharing services even if a provider didn't have a } \\
\text { rating? }\end{array}$ & 5.2 & 15.1 & 79.7 \\
\hline
\end{tabular}

Dealing with the responses to the question "Would you use sharing services even if a provider didn't have a rating?" we have to state that trust is extremely important. Here, up to $80 \%$ of respondents put clear statement that rating (obtained by customers) play a significant role in the sharing economy. Also other studies confirmed this fact $[7,11]$.

Looking to the future, we asked respondents if they were considering to offer the following shared economy services: Airbnb, BlaBlaCar, Uber, Carrivederci, and Yellow Melon. For each of the offered services, the majority of the sample stated that they did not consider offering it in the future (Table 3 ). We recorded the most negative attitudes in the case of the offer of money through the Yellow Melon service (up to 80\%). On the contrary, occasional (not permanent) car sharing (passenger ride) via BlaBlaCar recorded the highest share of positive responses (almost 30\%).

Table 3. Respondents considering to offer shared economy services $(n=232)$

\begin{tabular}{|c|c|c|c|}
\hline \multirow{2}{*}{} & \multicolumn{3}{|c|}{ Share of responses (\% of the sample) } \\
\cline { 2 - 4 } & Yes & Indifferent & No \\
\hline Airbnb & 23.3 & 20.7 & 56.0 \\
\hline BlaBlaCar & 29.7 & 23.7 & 46.6 \\
\hline Uber & 21.1 & 18.1 & 60.8 \\
\hline Carrivederci & 9.5 & 18.5 & 72.0 \\
\hline Yellow Melon & 3.0 & 16.4 & 80.6 \\
\hline
\end{tabular}

The contingency analysis pointed to differences in the willingness to offer sharing economy services between men and women. In general, in all services, a larger proportion of men were willing to offer them. The most striking was the difference in the willingness to offer Airbnb service - the share of men with a positive attitude was up to $15 \%$ higher compared to women. Interestingly, less than $1 \%$ of women (compared to more than $6 \%$ of men willing to offer this service) did not show a willingness to offer financial loans through Yellow Melon. The biggest difference in negative attitudes between the sexes was 
expressed by women in the offer of the BlaBlaCar service - about $9 \%$ higher share of women than men.

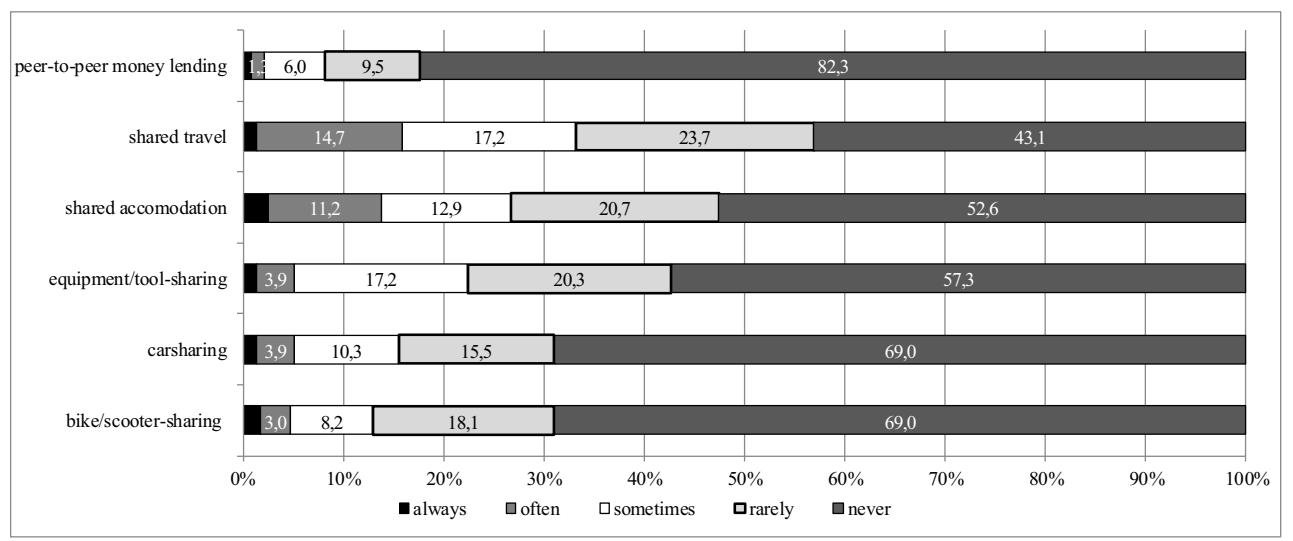

Fig. 2. Use of sharing economy services $(n=232)$.

Interestingly, high share of respondents stated that they never used indicated sharing economy services. More than $82 \%$ of respondents never utilised a community-driven peerto-peer lending platform ("Yellow melon" in Slovakia). Among the services, travel (car sharing) and accommodation seem to be the most popular, where about half of the respondents have some experience. There are trivial shares of permanent users of the observed services (who marked frequency "always").

\section{Conclusions}

The most important fact influencing interpretation of the results is the high share of students in the sample. Thus, the findings are applicable especially on the young generation (Generation Y). Overall, a relatively low percentage of the public uses the services of the shared economy. Most of the sample has no experience with the given services (ranging from $43-82 \%$ ). If respondents already use shared services, the largest share is with the frequency "rarely". They have the most experience with shared travel and accommodation. At the same time, these two areas (travel and accommodation) were the most frequent that respondents would consider for possible own business activities (offering the given services). It can be stated that the services of the sharing economy are still used to a small extent. Definitely the most important factor for the functioning of the sharing economy is trust, as only $5 \%$ of respondents would use the services of a provider that does not have a rating. In addition to the expressed opinion that the sharing economy is beneficial for improving the social status and economic level of the individual, a significant part of the respondents said that it is also beneficial for the state, self-government as well as contributes to the non-pollution of the environment. Placing unused or the underused assets of individuals on the market through platforms in the web environment thus bring a "pathway" in which many stakeholders have a win-win position. In that way, the answer to the title question would be: Yes, sharing looks good. The challenge is how to facilitate market conditions for its wider application and simultaneously build trust among its participants.

The authors would like to thank the Scientific Grant Agency of the Ministry of Education, Science, Research and Sport of the Slovak Republic and the Slovak Academy of Sciences, grant number 1/0674/19: "Proposal of a model for the eco-innovation integration into the innovation process of 
companies in Slovakia in order to increase their performance" and grant number 1/0666/19: "Determination of the development of a wood-based bioeconomy".

\section{References}

1. Kaputa, V., Lapin, K., Leregger, F., Gekic, H. (2020). Economic Dimensions of Environmental Citizenship. Chapter in book: Hadjichambis, A.Ch., Reis, P., Paraskeva-Hadjichambi, D., Činčera, J., Boeve-de Pauw, J., Gericke, N., Knippels, M.C. (Eds.) (2020). Conceptualizing Environmental Citizenship for 21st Century Education, Environmental Discourses in Science Education 4. Cham: Springer.

2. Matová, H., Triznová, M., Kaputa V., Šupín, M., Drličková E., Krahulcová, M. (2019). Consumers - global citizens from the CSR 2.0 perspective. SHS Web of Conferences, 74, 04015.

3. Belk, R. (2014). You are what you can access: sharing and collaborative consumption online. Journal of Business Research, 67(8), 1595-1600.

4. Činjarević, M., Kožo, A., Berberović, D. (2019). Sharing is Caring, and Millennials Do Care: Collaborative Consumption through the Eyes of Internet Generation. South East European Journal of Economics and Business, 14(1), 49-60.

5. Schwanholz, J., Leipold, S. (2020). Sharing for a circular economy? An analysis of digital sharing platforms' principles and business models. Journal of Cleaner Production, 269, 122327.

6. Piscicelli, L., Cooper, T., Fisher, T., (2015). The role of values in collaborative consumption: insights from a product-service system for lending and borrowing in the UK. Journal of Cleaner Production, 97, 21-29.

7. Lang, B., Botha, E., Robertson, J., Kemper, J.A, Dolan, R., Kietzmann J. (2020). How to grow the sharing economy? Create Prosumers! Australasian Marketing Journal, 28(3), 58-66.

8. Rotter, J. B., Pers, J. (1967). A new scale for the measurement of interpersonal trust. Journal of Personality, 35(4), 651-665.

9. Mackoy, R. D., Osland, G. E. (2004). Building internet trust: signalling through trustmarks. International Journal of Internet Marketing and Advertising, 1(3), 251267.

10. McCullough, M. E., Kilpatrick, S. D., Emmons, R. A, Larson, D. B. (2001). Is gratitude a moral affect. Psychological Bulletin, 127(2), 249-266.

11. Nadeem, W., Juntunen, M., Shirazi, F., Hajli, M. (2020). Consumers' value co-creation in sharing economy: The role of social support, consumers' ethical perceptions and relationship quality. Technological Forecasting and Social Change, 151, 119786.

12. Böcker, L., Meelen, T. (2017). Sharing for people, planet or profit? Analysing motivations for intended sharing economy participation. Environmental Innovation and Societal Transitions, 23, 28-39.

13. Bellotti, V., Ambard, A., Turner, D., Gossmann, C., Demkova, K., Carroll, J. M. (2015). A muddle of models of motivation for using peer-to-peer economy systems. In B. Begole, J. Kim (Eds.) Proceedings of the 33rd Annual ACM Conference on Human Factors in Computing Systems (pp. 1085-1094). New York: Association for Computing Machinery.

14. Niezgoda, A., Kowalska, K. (2020). Sharing Economy and Lifestyle Changes as Exemplified by the Tourism Market. Sustainability, 12, 5351. 
15. Buda, G., Pethes, B., Lehota, J. (2020). Dominant Consumer Attitudes in the Sharing Economy - A Representative Study in Hungary. Resources, 9(1), 1.

16. Na, Y. K., Kang, S., Jeong, H. Y. (2019). The Effect of Market Orientation on Performance of Sharing Economy Business: Focusing on Marketing Innovation and Sustainable Competitive Advantage. Sustainability, 11(3), 729.

17. Chang, W.L, Wang, J.Y. (2018). Mine is yours? Using sentiment analysis to explore the degree of risk in the sharing economy. Electronic Commerce Research and Applications, 28, 141-158.

18. Mittendorf, C., Berente, N., Holten, R. (2019). Trust in sharing encounters among millennials. Information Systems Journal, 29(5), 1083-1119.

19. Mont, O., Palgan, Y. V., Bradley, K., Zvolska, L. (2020). A decade of the sharing economy: Concepts, users, business and governance perspectives. Journal of Cleaner Production, 269, 122215. 